\title{
OPEN Author Correction: Past continental shelf evolution increased Antarctic ice sheet sensitivity to climatic conditions
}

\section{Florence Colleoni ${ }^{10}$, Laura De Santis, Enea Montoli, Elisabetta Olivo, Christopher C. Sorlien, Philip J. Bart, Edward G. W. Gasson, Andrea Bergamasco, Chiara Sauli, Nigel Wardell \& Stefano Prato}

Correction to: Scientific Reports https://doi.org/10.1038/s41598-018-29718-7, published online on 27 July 2018

The Acknowledgements section in this Article is incomplete.

"This work is supported by the PNRA national Italian project PNRA16_00016, "West Antarctic Ice Sheet History from Slope Processes - Eastern Ross Sea (WHISPERS)" and by the MAE bilateral Italy-US project US16GR04, "Global Sea Level Rise \& Antarctic Ice Sheet Stability predictions: guessing future by learning from past (GSLAISS)". We acknowledge the CMCC Foundation for providing computing resources. This research is a contribution to the SCAR PAIS program (https://www.scar.org/science/pais/)."

should read:

"This work is supported by OGS and CINECA under HPC-TRES Program Award Number 2018-01, by the PNRA national Italian projects PNRA16_00016 WHISPERS and PNRA16_00293 GLEVORS, and by the MAE bilateral Italy-US Project US16GR04, "Global Sea Level Rise \& Antarctic Ice Sheet Stability predictions: guessing future by learning from past (GSLAISS)". We acknowledge the CMCC Foundation for providing computing resources. We acknowledge the Antarctic Seismic Data Library (https://sdls.ogs.trieste.it) for providing open access to international marine seismic data. This research is a contribution to the SCAR PAIS program (https:// www.scar.org/science/pais/).”

\footnotetext{
(i) Open Access This article is licensed under a Creative Commons Attribution 4.0 International License, which permits use, sharing, adaptation, distribution and reproduction in any medium or format, as long as you give appropriate credit to the original author(s) and the source, provide a link to the Creative Commons license, and indicate if changes were made. The images or other third party material in this article are included in the article's Creative Commons license, unless indicated otherwise in a credit line to the material. If material is not included in the article's Creative Commons license and your intended use is not permitted by statutory regulation or exceeds the permitted use, you will need to obtain permission directly from the copyright holder. To view a copy of this license, visit http://creativecommons.org/licenses/by/4.0/.
}

(C) The Author(s) 2020 